\title{
Clinical utility of self-expanding stents in coronary artery disease
}

This article was published in the following Dove Press journal:

Research Reports in Clinical Cardiology

2 September 2015

Number of times this article has been viewed

\author{
Aditya R Boddu \\ Abilash R Balmuri \\ Masoor Kamalesh \\ Department of Cardiology, Krannert \\ Institute of Cardiology, Richard L \\ Roudebush VA Medical Center, \\ Indiana University School of Medicine, \\ Indianapolis, IN, USA
}

\begin{abstract}
The field of percutaneous coronary intervention (PCI) has evolved considerably since the era of percutaneous transluminal coronary angioplasty. Percutaneous transluminal coronary angioplasty with stenting has now become one of the cornerstones of treatment for coronary artery disease. The use of third-generation drug-eluting stents (DES) is currently the preferred method of treatment for different indications in patients with coronary artery disease. Self-expanding stents are routinely used in peripheral arterial disease, like external iliac and femoropopliteal percutaneous interventions. Self-expanding stents have been in use since the beginning of PCI. Although the first stent deployed was of the self-expanding variety, namely the Wallstent, balloon-expandable stents have become the stents of choice in the coronary arteries. The role of self-expanding stents in modern PCI is continuously evolving. This review discusses the utility of self-expanding stents in the treatment of specific subsets of coronary lesions.
\end{abstract}

Keywords: self-expanding stents, coronary artery disease, percutaneous coronary intervention, balloon-expandable stents, drug-eluting stents

\section{Differences between balloon-expandable and self-expanding stents}

Balloon-expandable and self-expanding stents have different mechanical and dynamic properties. While balloon-expandable stents reach their maximum diameter at the time of deployment (depending on the pressure of inflation), self-expanding stents continue to expand for a few days, reaching their maximum diameter several weeks post deployment. ${ }^{1}$

\section{General properties of self-expanding stents}

Self-expanding stents continue to expand post deployment, until they reach their appropriate size days to weeks later. The first-generation self-expanding stents were made of platinum and an alloy of cobalt-chromium. These foreshortened, resulting in incorrect stent deployment and a higher incidence of restenosis. Newer stent platforms have been designed to increase flexibility, radial strength, torsion, and lengthening or shortening of the vessel, with decreased rates of stent fracture and restenosis. There has been a remarkable improvement in stent design, with newergeneration self-expanding nitinol stents that have a superelastic metallic alloy of nickel and titanium. ${ }^{2}$ They have thinner struts, resulting in better deliverability ${ }^{3}$ and less in-stent restenosis.
Correspondence: Aditya R Boddu Department of Cardiology, Krannert Institute of Cardiology, $1800 \mathrm{~N}$ Capitol Ave, Suite 37I, Indianapolis, IN 46202, USA

Tel +I 3173618728

Email arboddu@iu.edu 


\section{Use of self-expanding stents in peripheral arterial disease}

Self-expanding stents are the most commonly placed stents in patients with femoropopliteal disease. One-year primary patency rates of $22 \%$ were demonstrated with the Palmaz stent and 30\% with the Wallstent. The newer stents have better long-term primary patency rates, ranging from $70 \%$ to $92 \%$. There are several randomized controlled trials comparing self-expanding nitinol stents with balloon angioplasty alone in the femoropopliteal segment and these have shown that the self-expanding nitinol stents offer improved durability, especially in the long femoropopliteal segment. The 4-EVER trial ${ }^{4}$ using the Astron Pulsar stent and the RESILIENT trial using the LifeStent ${ }^{5}$ showed primary patency rates of more than $80 \%$. In these trials, and other trials like FACT, ${ }^{6}$ the restenosis rate was lower with self-expanding stents compared with balloon angioplasty only.

\section{Potential benefits and utility in coronary artery disease}

Incomplete stent apposition can cause late stent thrombosis. ${ }^{7}$ Since self-expanding stents continue to enlarge days to weeks after implantation (until they reach their maximum size), they ensure correct apposition, minimizing the risk of stent malapposition, thereby reducing target vessel restenosis.

Stent sizing is a challenging issue, especially in complex lesions. In patients with myocardial infarction or heart failure, frequent undersizing of stents occurs due to the large thrombus burden and elevated left ventricular enddiastolic pressure causing vasoconstriction, thereby leading to underestimation of vessel size. Undersized stents have a higher incidence of restenosis, amongst other complications. Self-expanding stents may be a favorable alternative in these subsets of patients with coronary artery disease.

Self-expanding stents improve clinical outcomes as they induce less injury at implantation and achieve better vessel wall apposition. In one study by Aboodi et al, ${ }^{8}$ it was shown that the mechanism of stent expansion influences the degree of vascular injury and healing. In their study, self-expanding stents were associated with significantly less injury at 30 days, but by 180 days injury scores were comparable between selfexpanding stents and balloon-expandable stents. We now discuss the utility of self-expanding stents in the treatment of specific coronary artery lesions.

\section{Bifurcation lesions}

Stenting of bifurcation lesions is a complex issue, resulting in lower angiographic success rates due to compli- cations like acute vessel closure and a higher risk of restenosis. Novel stents are now being used to provide easier access to the side branch. The AXXENT trial ${ }^{9}$ evaluated the safety and efficacy of the self-expanding AXXESS biolimuseluting stent for the treatment of left main coronary artery (LMCA) bifurcation lesions, and showed good results in terms of stent thrombosis and target lesion revascularization at 6-month follow-up. In the DIVERGE IVUS substudy, ${ }^{10}$ the dedicated bifurcation AXXESS stent system demonstrated a significant increase in stent volume, with minimal neointimal formation and a low incidence of late incomplete stent apposition at 9 months. The stent thrombosis rate at 9 months was $1 \%$. An intravascular ultrasound comparison of the self-expanding Sideguard stent ${ }^{11}$ in the side branch versus a balloon-expandable stent in the main vessel in bifurcation lesions showed that acute lumen gain was less in the Sideguard stent due to less aggressive expansion of the main branch.

\section{Ectatic vessels and saphenous vein grafts}

Balloon-expandable stents usually dilate to only $4.5 \mathrm{~mm}$. Hence, self-expanding stents are theoretically more effective in treating ectatic vessels like saphenous vein grafts, which are often larger diameter vessels with thrombus. PCI in these vessels can lead to distal embolization, especially during stent deployment. In earlier studies, such as the WINS trial ${ }^{12}$ comparing the Wallstent with the Palmar Schatz stent, there was no difference in clinical outcome in hospital or at 6 months.

Trials such as SCORES, ${ }^{13}$ done in saphenous vein grafts, and a prospective randomized controlled trial by Tanaka et $\mathrm{al}^{14}$ demonstrated that the lower dilatation pressures seen with self-expanding stents may be associated with lower rates of target lesion revascularization. In the Symbiot II trial, ${ }^{15}$ the Symbiot self-expanding polytetrafluoroethylene membrane-covered stent was associated with a high procedural success rate $(97.4 \%)$ and a lower incidence of major adverse cardiac events (MACE) at 30 days (5.2\%) and 6 months $(14.3 \%)$, suggesting that this is a safe and effective choice in the treatment of saphenous vein graft lesions.

\section{Intervention in left main coronary artery}

In a small, single-center pilot study ${ }^{16}$ using the STENTYS self-expanding coronary stent in the LMCA, acute procedural and device success was achieved in $95 \%$ of cases with no edge dissection or adverse effects reported at 1 month. This 
suggested that use of the STENTYS self-expanding stent is a good option for treating complicated and often risky LMCA lesions. The Cappella stent has been used in LMCA bifurcation lesions, ${ }^{17}$ and excellent angiographic results were obtained with the Cappella coronary side branch stent in some patients with LMCA bifurcation lesions. Rewiring the side branch, delivery of equipment like balloons was noted to be easier in this study. However, due to infrequent use, production of this stent has ceased, including in the USA.

\section{Intermediate coronary lesions}

One of the first-in-human studies ${ }^{18}$ evaluating the safety and feasibility of the low pressure self-expanding nitinol-based vProtect luminal shield was in the treatment of intermediate coronary lesions. This study demonstrated that use of this particular self-expanding stent in noncomplex coronary lesions of intermediate severity was feasible, safe, and resulted in low rates of late loss and restenosis.

\section{Utility in acute myocardial infarction}

In patients with ST elevation myocardial infarction (STEMI), the presence of a large thrombus and vasoconstriction during the event often leads to underestimation of vessel size. A stent deployed at the time of an acute myocardial infarction may appear to be well apposed, but may actually be malapposed due to vessel relaxation occurring at a later time. ${ }^{19}$ Thus, a stent with continuous self-expandable and self-apposing properties could be adequately apposed and reduce stent malapposition, thereby reducing stent thrombosis. ${ }^{20}$ The APPOSITION trials ${ }^{21}$ studied the STENTYS self-expanding stent in patients with acute myocardial infarction, including patients with acute STEMI. ${ }^{22}$ Optical coherence tomography demonstrated that the STENTYS stent was well apposed to the vessel wall, with significantly lower stent malapposition when compared with the balloon-expandable group $(0.58 \%$ versus $5.46 \%$ ) and also with significantly lower rates of MACE. Of note was the increased risks of stent thrombosis (3.6\%) and MACE (3.6\%) without post-dilatation of the stent. Additional dilatation after STENTYS implantation reduced the stent thrombosis rate to $1.3 \%$ and the MACE rate to $2.5 \%$. The authors concluded that post-dilatation to ensure stent expansion may lead to an improvement in clinical results.

Newer third-generation DES and bioresorbable vascular scaffolds have also become popular in the treatment of patients with STEMI. The APPOSITION V trial ${ }^{23}$ was intended to be the first randomized trial powered on clinical endpoints to directly compare the STENTYS self-apposing stent with a conventional balloon-expandable stent in patients presenting with STEMI. However, enrollment in the APPOSITION V trial in the USA was slow due to overwhelming use of DES in primary PCI in STEMI patients in that country, so the trial was terminated early.

Another type of balloon-expandable stent called the M-Guard, which is a mesh-covered bare metal stent, has been studied in the setting of primary $\mathrm{PCI}^{24}$ for its ability to decrease the risk of distal embolization in thrombus-containing lesions. The M-Guard stent was proven to be effective, with low target vessel revascularization, low thrombosis rates at 1 and 12 months, less incidence of no reflow, a higher final TIMI flow, and myocardial blush gradient. However, use of this stent is still overall considerably less in primary PCI compared with the newer-generation DES.

\section{Patients with small vessel disease}

PCI in small vessel coronary artery disease is controversial and carries a worse prognosis than larger arteries due to increased restenosis. ${ }^{25}$ However, certain DES have been shown to be efficacious in small vessel PCI. ${ }^{26,27}$ Self-expanding stents could reduce the restenosis rate in small vessels due to a positive effect on remodeling. Studies using the Sparrow stent have demonstrated the safety and efficacy of self-expanding stents in small vessel coronary lesions. In one of the studies using intravascular ultrasound, the Sparrow stent was demonstrated to have more expansion with lower rates of restenosis. ${ }^{28}$

\section{Types of self-expanding stents Wallstent}

The Wallstent was the first self-expanding stent used in humans and also the first stent used in the coronary arteries. In the early 1990s, multiple European experiences with the Wallstent were reported. ${ }^{29}$ Initial indications included restenosis in coronaries treated with prior angioplasty, bypass grafts, and acute coronary occlusion secondary to initial dissection after balloon angioplasty. The Wallstent is made of a cobalt alloy with an inner platinum core. It has since been replaced by the Magic Wallstent. After deployment, these stents expand until there is an equilibrium between the elastic constraints of the vessel wall and the dilating force of the stent. In a study ${ }^{30}$ comparing Wallstent and balloonexpandable Palmaz-Schatz stents and measuring the impact of stent design on coronary wall geometry using quantitative coronary angiography and intracoronary ultrasound measurements, the Wallstent showed significant stent expansion post deployment with positive vessel remodeling. 


\section{Symbiot stent}

The Symbiot stent was developed to reduce distal embolization, restenosis in saphenous vein graft interventions. The SYMBIOT II trial ${ }^{15}$ demonstrated that treatment of saphenous vein graft lesions with the Symbiot stent was safe and effective. The MACE rate in this trial (5.3\%) was significantly lower than the $13.5 \%$ reported in the WINS trial.

\section{STENTYS stent}

The STENTYS self-expanding coronary stent has been used in patients with myocardial infarction. ${ }^{21}$ The STENTYS stent was well apposed to the wall on optical coherence tomography imaging when compared with balloon-expandable stents. It has also been studied in bifurcation lesions, ${ }^{31}$ especially in LMCA bifurcation lesions, and is associated with increased procedural success and decreased MACE rates.

\section{Protect stent}

The Protect luminal shield self-expanding device has been used for mechanical stabilization of vulnerable plaques in intermediate nonobstructive coronary lesions. ${ }^{18}$

\section{Sparrow stent}

The Sparrow stent is a self-expanding nitinol stent developed to treat lesions in the small coronary arteries. ${ }^{32}$

\section{AXXESS stent}

The AXXESS bifurcation system is a self-expanding dedicated bifurcation stent system. The AXXESS system covers the ostium of both distal branch vessels, and is designed to adjust to the anatomy of the vessel at the bifurcation carina. The DIVERGE trial ${ }^{33}$ studied the AXXESS selfexpanding stent system. In the AXXESS group, the lumen of the proximal main vessel was noted to be significantly augmented.

\section{Capella Sideguard stent}

The Cappella Sideguard stent is a dedicated stent used for treatment of the side branch in bifurcation lesions, ${ }^{17}$ including LMCA bifurcation lesions.

\section{Igaki-Tamai stent}

The Igaki-Tamai stent is a biodegradable stent made of a poly-L-lactic acid monopolymer with a biodegradable period of $12-18$ months. In a small study ${ }^{34}$ comparing these stents with balloon-expandable stents, there were no differences in MACE, except for repeat revascularization at 6 months.

\section{Discussion}

The design and properties of self-expanding stents make them potentially suitable for interventions in various complex coronary lesions, including vein graft lesions, bifurcation lesions, tortuous vessels, left main disease, small vessels, and lesions causing STEMI. Self-expanding stents have already been approved in Europe ${ }^{35}$ for use in specific situations, such as bifurcation lesions and coronary artery bypass graft interventions.

Self-expanding stents can overcome many of the inherent problems of balloon-expandable stents, such as high pressure balloon inflations, overexpansion of a narrow segment distal to the stent, increasing the risk of an edge dissection, and underexpansion of a proximal segment resulting in poor stent apposition. ${ }^{36}$ Limitations of self-expanding stents include difficulty with precise placement, especially in ostial lesions, and inability to oversize the stent beyond its "set" diameter. These stents, being bulkier, may also be difficult to deliver. The earlier stents, such as the Wallstent, are associated with an increased rate of restenosis. ${ }^{37}$

Currently, the third-generation DES, which are balloonexpandable stents, are the treatment of choice for all coronary lesions, including patients with acute myocardial infarction. Bioresorbable vascular scaffolds have also become popular in the treatment of coronary artery disease. ${ }^{38} \mathrm{New}$-generation metallic DES (everolimus/biolimus) were not superior to bioresorbable vascular scaffolds in terms of angiographic late lumen loss or clinical outcomes in the randomized EVERBIO II ${ }^{39}$ trial. Their use has been particularly studied in patients with STEMI. ${ }^{40}$

With the advent of these third-generation DES and drugcoated stents, the use of self-expanding stents in coronary artery disease has become less and limited. Use and production of some self-expanding stents, such as the Cappella stent, has ceased due to infrequent use in left main bifurcation coronary artery lesions. Larger randomized controlled trials with long-term follow-up, and continuing research to further improve the design of selfexpanding stents and platforms for stent delivery are needed. The unique properties of self-expanding stents make them promising alternatives in the treatment of specific coronary lesions.

\section{Disclosure}

The authors have no financial disclosures or conflicts of interest related to this topic.

\section{References}

1. Lu H, Grundeken MJ, Koch KT, Wykrzykowska JJ. Self-expanding intracoronary stents in the treatment of coronary artery disease: new developments and future directions. Minerva Cardioangiol. 2013; 61(5):547-562. 
2. Grenadier E, Shofti R, Beyar M, et al. Self-expandable and highly flexible nitinol stent: immediate and long-term results in dogs. Am Heart J. 1994;128(5):870-878.

3. Kim DB, Choi H, Joo SM, et al. A comparative reliability and performance study of different stent designs in terms of mechanical properties: foreshortening, recoil, radial force, and flexibility. Artif Organs. 2013;37(4):368-379.

4. Bosiers M, Deloose K, Callaert J, et al. 4-French-compatible endovascular material is safe and effective in the treatment of femoropopliteal occlusive disease: results of the 4-EVER trial. $J$ Endovasc Ther. 2013;20(6):746-756.

5. Laird JR, Katzen BT, Scheinert D, et al. Nitinol stent implantation versus balloon angioplasty for lesions in the superficial femoral artery and proximal popliteal artery: twelve-month results from the RESILIENT randomized trial. Circ Cardiovasc Interv. 2010;3(3):267-276.

6. Zeller T, Tiefenbacher C, Steinkamp HJ, et al. Nitinol stent implantation in TASC A and B superficial femoral artery lesions: the Femoral Artery Conformexx Trial (FACT). J Endovasc Ther. 2008;15(4):390-398.

7. Cook S, Eshtehardi P, Kalesan B, et al. Impact of incomplete stent apposition on long-term clinical outcome after drug-eluting stent implantation. Eur Heart J. 2012;33(11):1334-1343.

8. Aboodi MS, Milewski K, TellezA, et al. Long term impact of balloon postdilatation on neointimal formation: an experimental comparative study between second-generation self-expanding versus balloon-expandable stent technologies. Catheter Cardiovasc Interv. 2014;83(3):397-404.

9. Lucisano L, Calcagno S, Pennacchi M, Stio RE, Mancone M, Sardella G. Results of the self-expandable BA9 stent for treatment of large angle coronary bifurcation. Minerva Cardioangiol. 2014;62(1):19-27.

10. Buysschaert I, Sanidas E, Hasegawa T, et al. Baseline and 9 months IVUS analysis of the bifurcation-dedicated biolimus A9-eluting Axxess stent system: the DIVERGE IVUS substudy. Catheter Cardiovasc Interv. 2014;84(7):1062-1070.

11. Ma S, Maehara A, Hauptmann KE, et al. Intravascular ultrasound comparison of the self-expanding Sideguard stent in the side branch versus a balloon-expandable stent in the main vessel to assess mechanisms of acute lumen gain in bifurcation lesions. Catheter Cardiovasc Interv. 2013;82(5):748-754

12. Safian RD, Kaplan B, Schreiber T, et al. Final results of the randomized Wallstent endoprosthesis in saphenous vein graft trial. $J$ Am Coll Cardiol. 1999;33(37A).

13. Kandzari DE, Goldberg S, Schwartz RS, Chazin-Caldie M, Sketch MH Jr. Clinical and angiographic efficacy of a self-expanding nitinol stent in saphenous vein graft atherosclerotic disease: the Sten Comparative Restenosis (SCORES) Saphenous Vein Graft Registry. Am Heart J. 2003;145(5):868-874.

14. Tanaka S, Watanabe S, Matsuo H, et al. Prospective randomized trial comparing a nitinol self-expanding coronary stent with low-pressure dilatation and a high-pressure balloon expandable bare metal stent Heart Vessels. 2008;23(1):1-8.

15. Laarman GJ, Kiemeneij F, Mueller R, Guagliumi G, Cobaugh M, Serruys PW. Feasibility, safety, and preliminary efficacy of a novel ePTFE-covered self-expanding stent in saphenous vein graft lesions: the Symbiot II trial. Catheter Cardiovasc Interv. 2005;64(3):361-368.

16. Smolka G, Wanha W, Roleder T, Pluta A, Ochala A. Treatment of left main coronary artery stenosis with the STENTYS self-expandable drug-eluting stent - a pilot registry. Postepy Kardiol Interwencyjnej. 2014;10(4):226-230

17. Egred M. A Novel use of the dedicated sideguard nitinol self expanding Cappella stent for the treatment of left main stem bifurcation. Int $J$ Cardiol. 2013;168(3):2921-2924.

18. Granada JF, Milewski K, Uribe MP, et al. First clinical evaluation of a luminal self-expanding shield in patients with intermediate coronary lesions. EuroIntervention. 2011;7(7):780-788.

19. van Geuns RJ, Tamburino C, Fajadet J, et al. Self-expanding versus balloonexpandable stents in acute myocardial infarction: results from the APPOSITION II study: self-expanding stents in ST-segment elevation myocardial infarction. JACC Cardiovasc Interv. 2012;5(12): 1209-1219.
20. Hong MK, Mintz GS, Lee CW, et al. Late stent malapposition after drug-eluting stent implantation: an intravascular ultrasound analysis with long-term follow-up. Circulation. 2006;113(3): 414-419.

21. Amoroso G, van Geuns RJ, Spaulding C, et al. Assessment of the safety and performance of the STENTYS self-expanding coronary stent in acute myocardial infarction: results from the APPOSITION I study. EuroIntervention. 2011;7(4):428-436.

22. Wijns W, Pyxaras SA. Self-expanding stents for primary percutaneous coronary intervention during acute myocardial infarction: did we find the right indication ... at last! JACC Cardiovasc Interv. 2012;5(12):1220-1222.

23. Grundeken MJ, Lu H, Mehran R, et al. APPOSITION V: STENTYS coronary stent system clinical trial in subjects with ST-segment elevation myocardial infarction - rationale and design. Am Heart $J$. 2014;168(5):652-660.

24. Anthopoulos P, Alexanian I, Karabela G, et al. Impact on myocardial reperfusion using the M-Guard stent in primary percutaneous coronary intervention for ST-elevation myocardial infarction. Int $J$ Cardiol. 2014;176(2):546-547.

25. Akiyama T, Moussa I, Reimers B, et al. Angiographic and clinical outcome following coronary stenting of small vessels: a comparison with coronary stenting of large vessels. J Am Coll Cardiol. 1998;32(6): $1610-1618$.

26. Bucalo R, Capranzano P, Conti G, et al. Sirolimus versus paclitaxel-eluting stents in small coronary vessels: long-term outcomes from a single-center registry. J Cardiovasc Med (Hagerstown). 2010;11(5): 365-368.

27. Lau KW, Ding ZP, Sim LL, Sigwart U. Clinical and angiographic outcome after angiography-guided stent placement in small coronary vessels. Am Heart J. 2000;139(5):830-839.

28. Chamie D, Costa JR Jr, Abizaid A, et al. Serial angiography and intravascular ultrasound: results of the SISC Registry (Stents In Small Coronaries). JACC Cardiovasc Interv. 2010;3(2):191-202.

29. Strauss BH, Serruys PW, Bertrand ME, et al. Quantitative angiographic follow-up of the coronary Wallstent in native vessels and bypass grafts (European experience - March 1986 to March 1990). Am J Cardiol. 1992;69(5):475-481.

30. Konig A, Schiele TM, Rieber J, Theisen K, Mudra H, Klauss V. Stent design-related coronary artery remodeling and patterns of neointima formation following self-expanding and balloon-expandable stent implantation. Catheter Cardiovasc Interv. 2002;56(4):478-486.

31. Verheye S, Ramcharitar S, Grube E, et al. Six-month clinical and angiographic results of the STENTYS(R) self-apposing stent in bifurcation lesions. EuroIntervention. 2011;7(5):580-587.

32. Abizaid AC, de Ribamar Costa Junior J, Whitbourn RJ, Chang JC. The CardioMind coronary stent delivery system: stent delivery on a .014" guidewire platform. EuroIntervention. 2007;3(1):154-157.

33. Verheye S, Agostoni P, Dubois CL, et al. 9-month clinical, angiographic, and intravascular ultrasound results of a prospective evaluation of the AXXESS self-expanding biolimus A9-eluting stent in coronary bifurcation lesions: the DIVERGE (Drug-Eluting Stent Intervention for Treating Side Branches Effectively) study. J Am Coll Cardiol. 2009; 53(12):1031-1039.

34. Tamai H, Igaki K, Kyo E, et al. Initial and 6-month results of biodegradable poly-1-lactic acid coronary stents in humans. Circulation. 2000;102(4):399-404.

35. Jilaihawi H, Farah B, Laborde JC. The use of self-expanding stents in coronary bifurcations and beyond: a paradigm revisited. EuroIntervention. 2009;4(5):669-675.

36. Arjomand H, Roukoz B, Goldberg S. Self-expanding stents in treatment of coronary artery disease. In: Ellis SG, Holmes DR Jr, editors. Strategic Approaches in Coronary Intervention. 3rd ed. Philadelphia, PA, USA: Lippincott, Williams \& Wilkins; 2005.

37. Foley DP, Pieper M, Wijns W, et al. The influence of stent length on clinical and angiographic outcome in patients undergoing elective stenting for native coronary artery lesions; final results of the Magic 5L Study. Eur Heart J. 2001;22(17):1585-1593. 
38. Serruys PW, Chevalier B, Dudek D, et al. A bioresorbable everolimuseluting scaffold versus a metallic everolimus-eluting stent for ischaemic heart disease caused by de-novo native coronary artery lesions (ABSORB II): an interim 1-year analysis of clinical and procedural secondary outcomes from a randomised controlled trial. Lancet. 2015; 385(9962):43-54.
39. Puricel S, Arroyo D, Corpataux N, et al. Comparison of everolimus- and biolimus-eluting coronary stents with everolimus-eluting bioresorbable vascular scaffolds. J Am Coll Cardiol. 2015;65(8):791-801.

40. Scalone G, Brugaletta S, Gomez-Monterrosas O, Otsuki S, Sabate M. ST-segment elevation myocardial infarction. Circ J. 2015;79(2): $263-270$.

\section{Publish your work in this journal}

Research Reports in Clinical Cardiology is an international, peerreviewed, open access journal publishing original research, reports, editorials, reviews and commentaries on all areas of cardiology in the clinic and laboratory. The manuscript management system is completely online and includes a very quick and fair peer-review system.
Visit http://www.dovepress.com/testimonials.php to read real quotes from published authors. 